\title{
Arch reconstruction after a previous ascending-to-descending aortic bypass for coarctation of the aorta
}

\author{
Alduz S. Cabasa, MD, ${ }^{a}$ Thomas C. Bower, MD, ${ }^{\mathrm{b}}$ and Alberto B. Pochettino, $\mathrm{MD}^{\mathrm{a}}$ \\ From the Divisions of a Cardiovascular Surgery and ${ }^{\mathrm{b}}$ Vascular Surgery, Department of Surgery, Mayo Clinic, \\ Rochester, Minn. \\ Disclosures: Authors have nothing to disclose with regard to commercial support. \\ Received for publication Jan 8, 2016; accepted for publication Jan 15, 2016; available ahead of print Feb 10, 2016. \\ Address for reprints: Alduz S. Cabasa, MD, Division of Cardiothoracic Surgery, Mayo Clinic Rochester, 200 First \\ St SW, Rochester, MN 55905 (E-mail: cabasa.alduz@mayo.edu). \\ J Thorac Cardiovasc Surg 2016;151:1760-3 \\ 0022-5223/\$36.00 \\ Copyright (c) 2016 by The American Association for Thoracic Surgery \\ http://dx.doi.org/10.1016/j.jtcvs.2016.01.027
}

Video clip is available online.

If left untreated, coarctation of the aorta may lead to early mortality. ${ }^{1,2}$ Several reparative techniques have been described for "complex coarctation," including the extraanatomic aortic bypass. 1,2 However, initial repairs are often complicated by prosthetic graft infection, recoarctation, and pseudoaneurysm formation, requiring reintervention. ${ }^{3-5}$ Because of the complexity of the second operation, the approach has always led to discussion among experts. ${ }^{1}$ We present a surgical management for an anastomotic pseudoaneurysm after a previous ascendingto-descending aortic bypass. We aim to demonstrate that surgical reintervention is a safe option with respectable early results.

\section{CLINICAL SUMMARY}

A 47-year-old man with coarctation of the aorta had undergone 2 previous thoracotomies, including placement of an ascending-to-descending 16-mm Dacron polyester fabric graft bypass 20 years previously. Recent recurrent headaches and epistaxis compelled him to consult our clinic. A computed tomographic (CT) angiogram showed a $6.0-\mathrm{cm}$ pseudoaneurysm at the distal anastomosis (Figure 1).

Video 1 illustrates the surgical procedure performed. Through a trapdoor incision, the ascending aorta, aortic arch, and descending aorta were exposed (Figure 2). Standard cannulation of the aorta and right atrium was done. The patient was cooled to deep hypothermia, and circulatory arrest was initiated. Selective antegrade cerebral perfusion was instituted. The distal aorta-graft anastomosis was completed, and perfusion to the lower body was reinitiated. Proximal aortic anastomosis with incorporation of the head vessels followed. Selective antegrade cerebral perfusion (Figure 4).

\section{CONCLUSIONS}

\section{References}

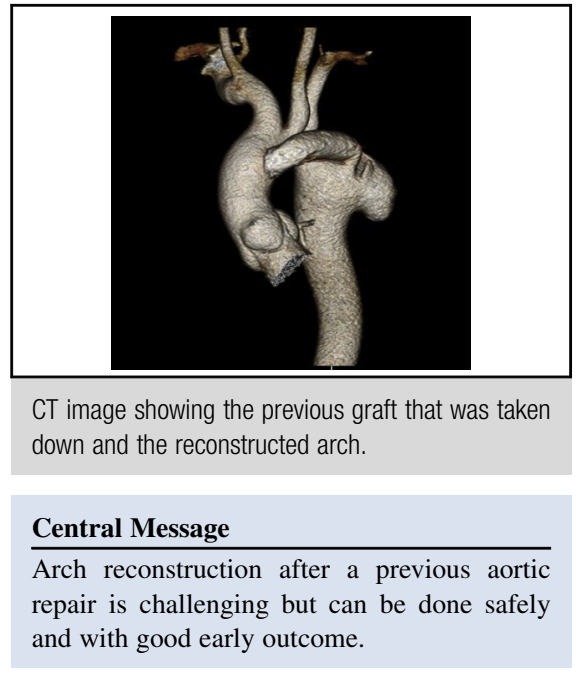

See Editorial Commentary page 1764.

was discontinued, the graft was cannulated, and flow to the upper body was resumed. The proximal and distal grafts were then anastomosed together. Decannulation and hemostasis completed the procedure (Figure 3). The patient had hoarseness develop, which was successfully treated with injection laryngoplasty. A postoperative CT angiogram showed no evidence of complications or pseudoaneurysm, and the patient was discharged on postoperative day 8

Arch reconstruction after a previous ascending-todescending aortic bypass for coarctation of the aorta can be done safely through a trapdoor incision with good early outcome and minimal complications.

1. von Kodolitsch Y, Aydin MA, Koschyk DH, Loose R, Schalwat I, Karck M, et al. Predictors of aneurysmal formation after surgical correction of aortic coarctation. J Am Coll Cardiol. 2002;39:617-24.

2. Dodge-Khatami A, Backer CL, Mavroudis C. Risk factors for recoarctation and results of reoperation: a 40-year review. J Card Surg. 2000;15:369-77.

3. Liu JY, Kowalski R, Jones B, Konstantinov I, Cheung M, Donath S, et al. Moderately hypoplastic arches: do they reliably grow into adulthood after conventional coarctation repair? Interact Cardiovasc Thorac Surg. 2010;10:582-6.

4. Spielvogel D, Strauch J, Minanov O, Lansman S, Griepp R. Aortic arch replacement using a trifurcated graft and selective cerebral antegrade perfusion. Ann Thorac Surg. 2002;74:1810-4; discussion S1825-32.

5. Silva J, Maroto L, Carnero M, Vilacosta I, Cobiella J, Villagrán E, et al. Ascending aorta and aortic root reoperations: are outcomes worse than first time surgery. Ann Thorac Surg. 2010;90:555-60. 


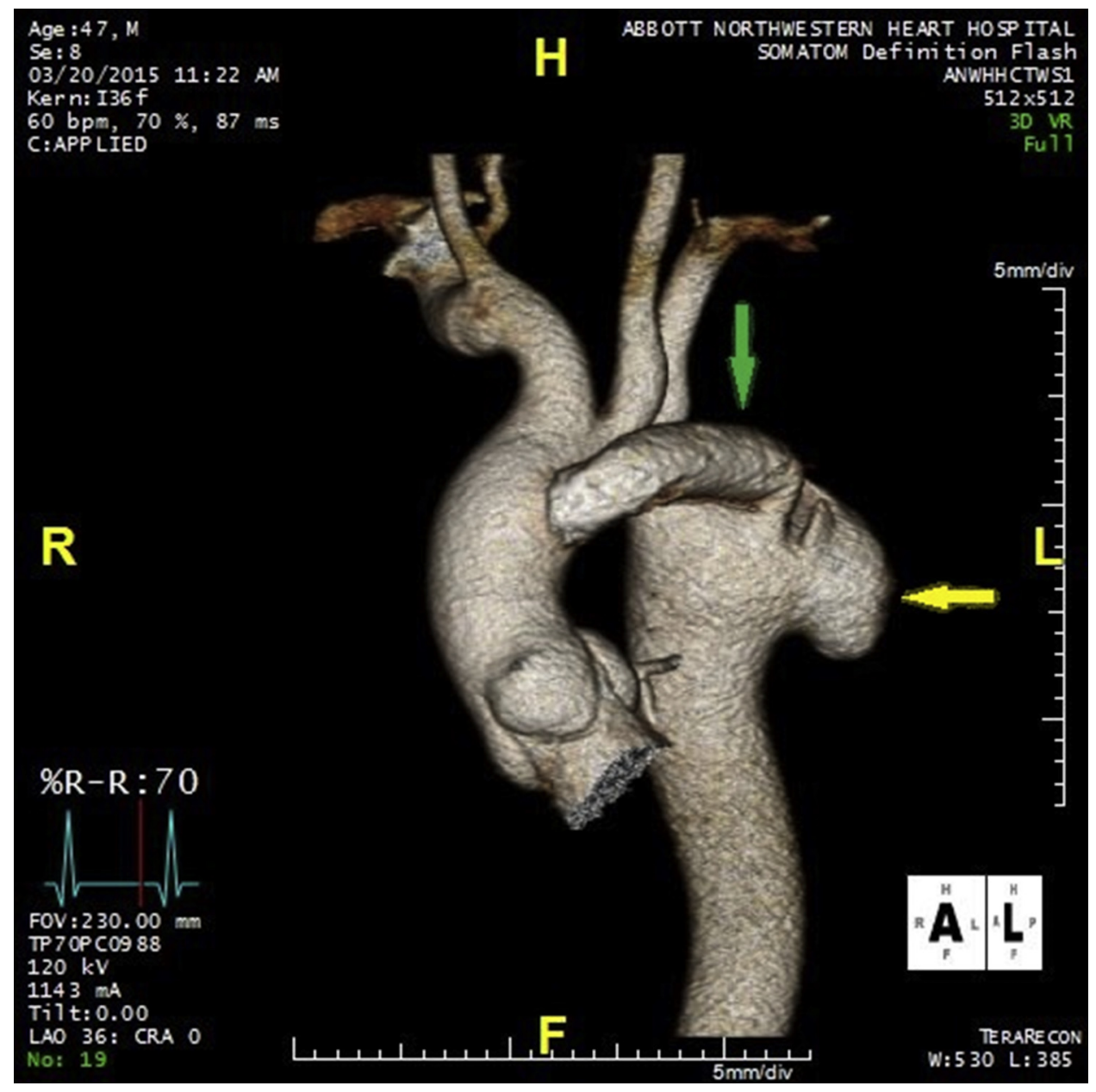

FIGURE 1. Three-dimensional reconstruction of the preoperative chest computed tomographic scan showing the graft conduit (green arrow) bypassing the coarctation of the aorta (not shown) located between the left common carotid artery and left subclavian artery. The 6.0-cm pseudoaneurysm (yellow arrow) at the distal anastomosis site is also shown in the 3-dimensional reconstruction. 


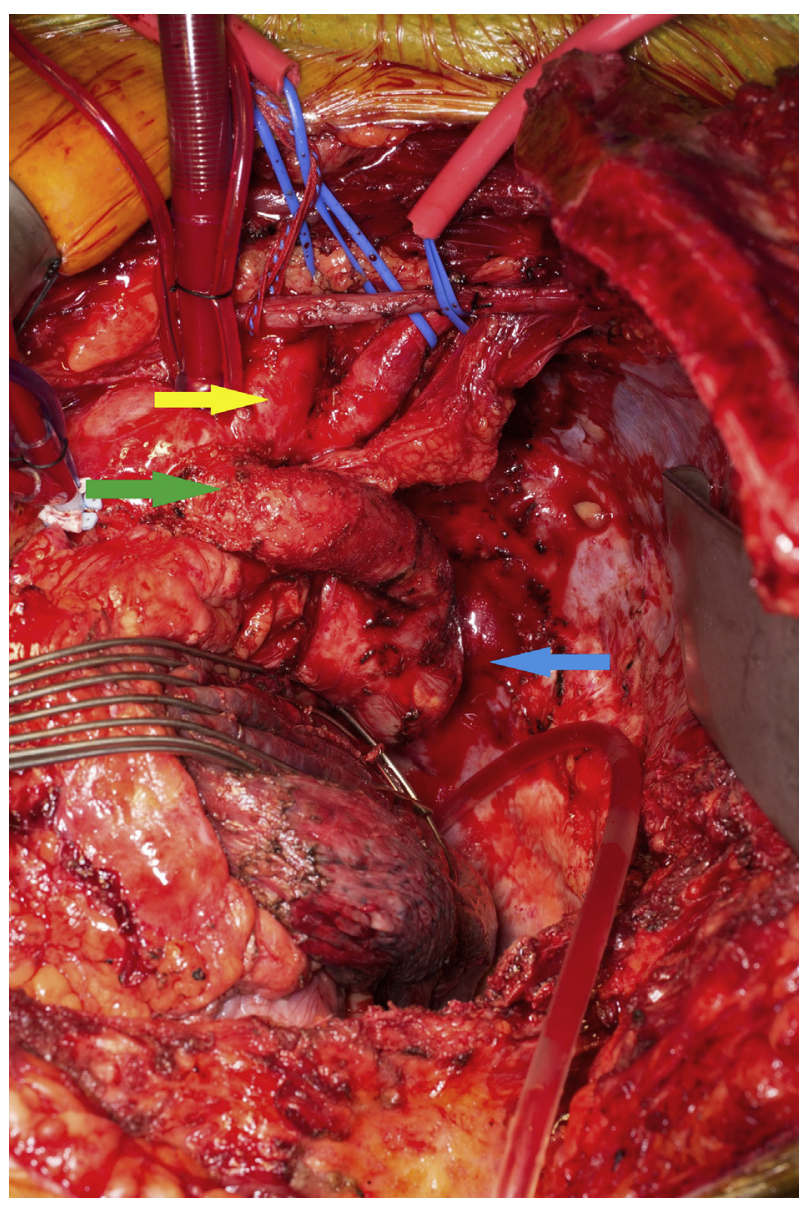

FIGURE 2. Postdissection intraoperative picture showing the graft conduit (green arrow), the arch branches (yellow arrow), and the pseudoaneurysm (blue arrow).

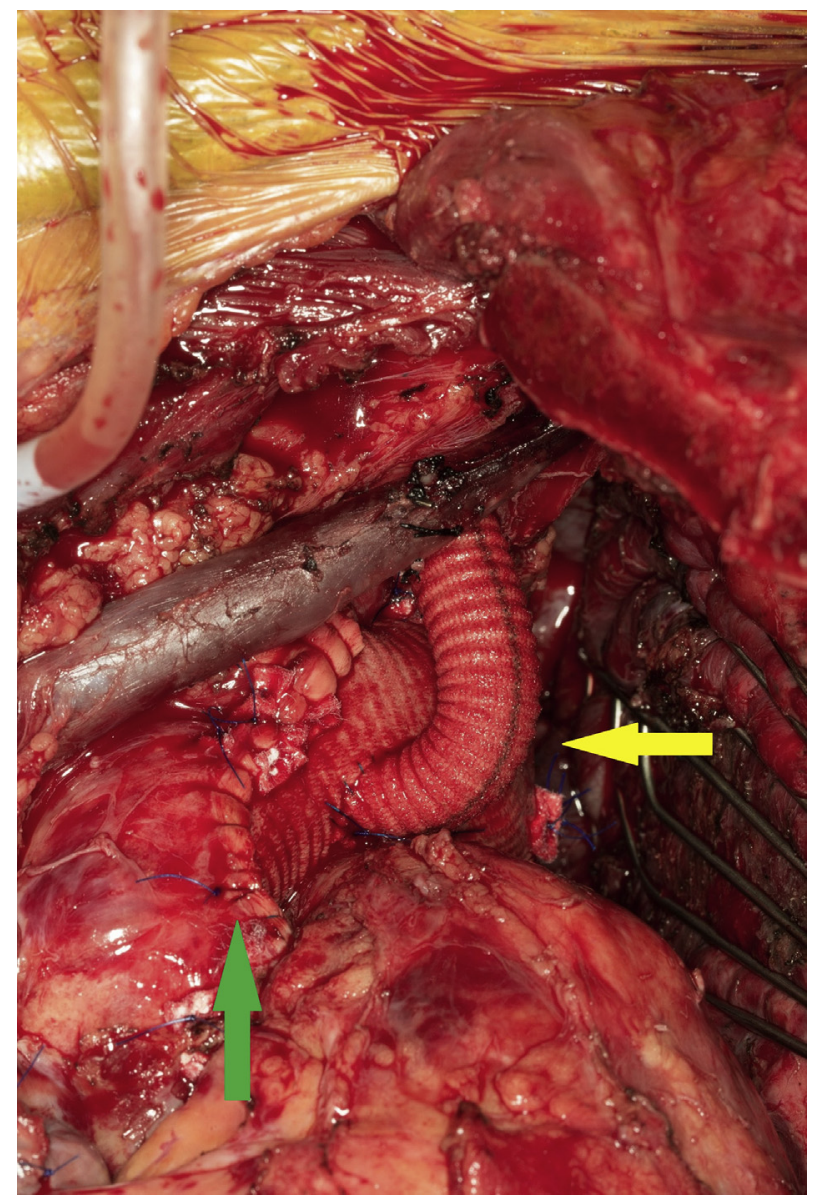

FIGURE 3. Postreconstruction intraoperative picture showing the anastomosis to the ascending aorta (green arrow) of the new Dacron polyester fabric graft. The branch to the left subclavian artery (yellow arrow) was anastomosed to the side of the neoarch. 


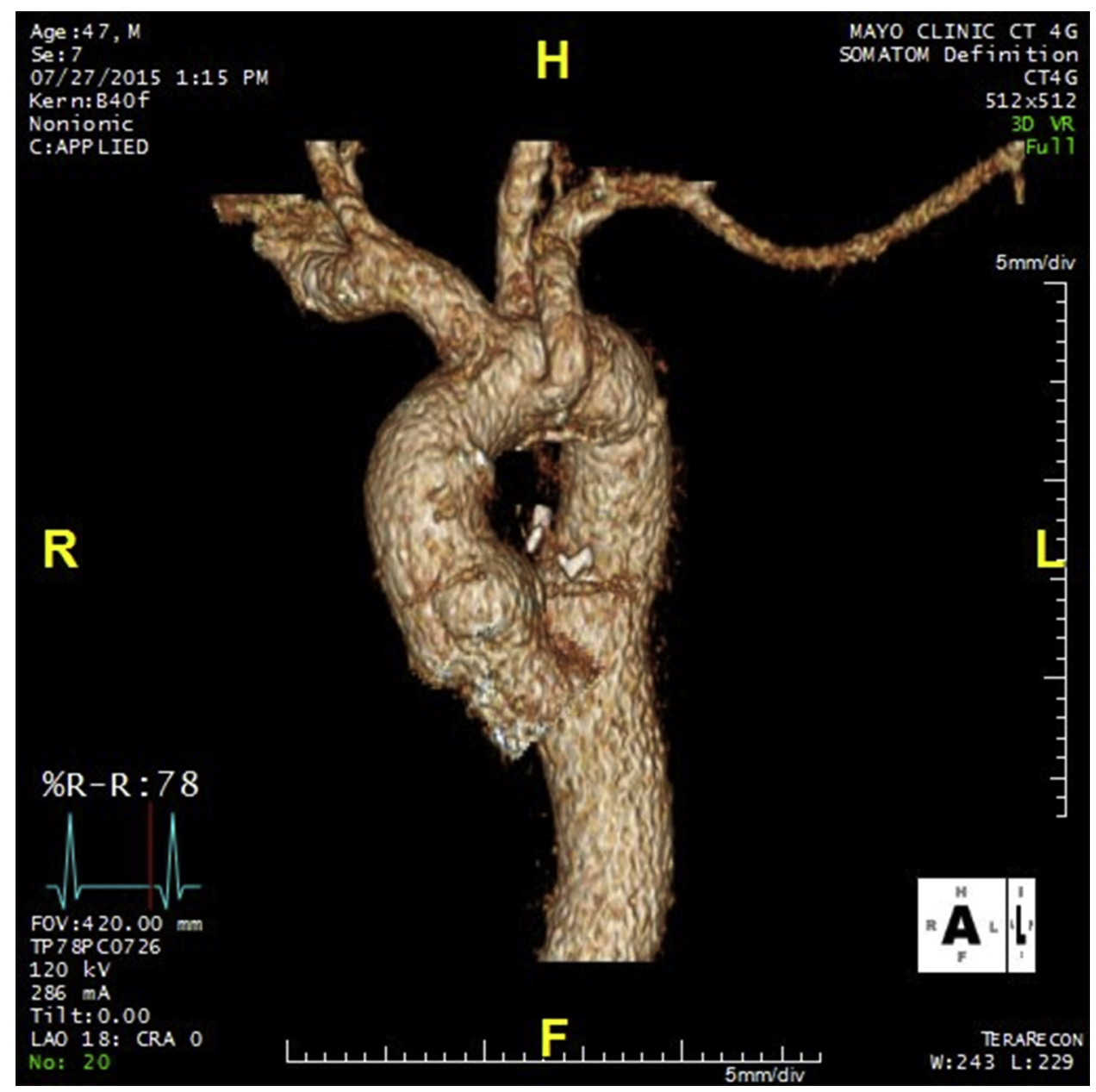

FIGURE 4. Three dimensional reconstruction of the postoperative computed tomographic scan showing the new arch and its branches. 